\title{
ESTRATEGIAS FAMILIARES DE HOMBRES Y MUJERES CON VIH QUE BUSCAN ATENDER NECESIDADES MATERIALES EN LA REGIÓN DEL SOCONUSCO, CHIAPAS
}

\author{
Family Strategies of Men and Women with HIV Who Seek to Meet Material Needs in the Soconusco, \\ Chiapas
}

\author{
Francisco Chong-Villarreal \\ Carmen Fernández-Casanueva \\ Laura Huicochea-Gómez \\ Guadalupe del Carmen Álvarez-Gordillo \\ René Leyva-Flores
}

\begin{abstract}
Resumen: En este estudio se entrevistó a siete mujeres y doce hombres con virus de inmunodeficiencia humana (VIH) en situación de pobreza, en la región del Soconusco, estado de Chiapas. Se analizaron las estrategias familiares que utilizan para cubrir sus necesidades materiales. Pese a que el estigma asociado al VIH y Síndrome de Inmunodeficiencia Humana (SIDA) está presente en su vida, se encontró que la familia extensa - padres, hijos, abuelos, tíos, nietos - de aquellas personas, después de un proceso de readaptación al grupo, juega un papel importante para satisfacer las necesidades de alimentación, transporte y vivienda.
\end{abstract}

Palabras clave: familia extensa, personas con VIH, pobreza, recurso social, agencia.

Abstract: In this study, we interviewed seven women and twelve men with Human Immunodeficiency Virus (HIV) living in poverty in the Soconusco region in the state of Chiapas. Family strategies are analyzed below to cover their material needs. Although the stigma associated with HIV and Human Immunodeficiency Syndrome (AIDS) is present in your life, it was found that the extended family - parents, children, grandparents, uncles, grandchildren - of those people, after an adaptation process, play an important role to meet the needs for food, transportation and housing.

Keywords: extended family, people with HIV, poverty, social action, agency.

Francisco Chong Villarreal, estudiante de doctorado en ecología y desarrollo
sustentable por El Colegio de la Frontera Sur, unidad Tapachula, México. Temas
de especialización: discriminación asociada al VIH y homosexualidad. Correo
electrónico: chongpac@yahoo.com.mx.
Carmen Fernández Casanueva, investigadora de El Colegio de la Frontera
Sur ECOSUR, unidad Tapachula, México. Temas de especialización:
transnacionalismo, rol de género y redes sociales de procesos migratorios. Correo
electrónico: cfernandez@ecosur.mx.
Laura Huicochea Gómez, investigadora de El Colegio de la Frontera Sur, unidad
Campeche, México. Temas de especialización: Interculturalidad en salud,
medicina tradicional, procesos culturales en salud de poblaciones antiguas. Correo
electrónico: lhuicochea@ecosur.mx.
GuadalupedelCarmen Álvarez Gordillo, investigadora de El Colegio de la Frontera
Sur, unidad SanCristóbal de Las Casas, Chiapas, México. Temas de especialización:

enfermedades consideradas problemas de salud pública, gestion de riesgos de desastres. Correo electrónico: galvarez@ecosur.mx.

René Leyva Flores, investigador del Instituto Nacional de Salud Pública, México. Temas de especialización: derechos sexuales y reproductivos de poblaciones migrantes. VIH/SIDA. Correo electrónico: rleyva@insp.mx.

Enviado a dictamen: 15 de febrero de 2013.

Aprobación: 16 de agosto de 2013.

Revisiones: 2. 
Francisco Chong-Villarreal, Carmen Fernández-Ćasanueva, Laura Huicochea-Gómez, Guadalupe del Carmen Álvarez-Gordillo, René LeYva-FLores

\section{Introducción}

L a noción de vulnerabilidad social en VIH, entendida como la "fracción de factores de riesgo para adquirir la infección del VIH y para su diseminación que es casi inmodificable por parte del individuo" (Bronfman et al., 2004: 21), ha sido el hilo conductor de gran parte de los estudios que sobre el VIH y el SIDA se han llevado a cabo en el estado de Chiapas, México (Evangelista y Kauffer, 2007; García et al., 2007; Villa et al., 2004). En estos estudios se enfatizan los factores de riesgo frente al virus que provoca el SIDA a los que se enfrentan grupos como los hombres homosexuales y heterosexuales jóvenes, las amas de casa y los migrantes en tránsito. En ese sentido, se ha documentado, por ejemplo, el alto riesgo que existe en el contexto del trabajo sexual por la violencia o el alto consumo de alcohol y drogas (Villa et al., 2004; Quintino et al., 201la; Quintino et al., 2011b). Por su parte, las mujeres indígenas cuyas parejas emigran a los Estados Unidos y posteriormente regresan se exponen al riesgo de adquirir alguna infección sexual porque sus parejas generalmente viven una sexualidad sin protección con otras personas (García et al., 2007; Evangelista et al., 2007). Asimismo, las normas socioculturales condicionan a jóvenes indígenas a iniciarse sexualmente en un contexto social donde es frecuente la migración de los jóvenes a los Estados Unidos y donde persiste la desinformación y una visión estigmatizada del VIH (Evangelista y Kauffer, 2007). Estos estudios destacan las desventajas que representan la violencia, la falta de información, la pobreza y el consumo de alcohol y drogas que, junto al estigma asociado al VIH, incrementan el riesgo para adquirirlo.

El estigma relacionado al VIH (Parker y Aggleton, 2002) tiene un efecto inutilizador que limita las posibilidades para resistir a las fuerzas que discriminan. Entre sus consecuencias para las personas afectadas están la perdida de trabajo, de vivienda, de estatus social, y de pareja y otros familiares (DFID, 2007; Ogden y Niblade, 2005; Fasce, 2006). La falta de apoyo social se asocia a la no adherencia al tratamiento, lo que ocasiona problemas de salud que pueden conducir a la muerte (Vega y González, 2009). En Chiapas, estado que a nivel nacional ocupa el séptimo lugar en muertes por complicaciones del SIDA (ISECH, 2012), además del estigma en comunidades indígenas, se ha documentado también la insensibilidad y negligencia administrativas en la atención a pacientes con VIH dentro de los centros de atención médica (Gómez et al., 2012). En este trabajo, que tiene como objetivo analizar el papel de las estrategias familiares para cubrir necesidades de vivienda, alimentación y transporte en una situación económica precaria, centramos la atención en las acciones que llevan a cabo las personas que reciben atención médica en el Hospital General de Huixtla, de la Secretaria de Salud, para resolver sus necesidades materiales. Sostenemos que estas acciones, pese a la pobreza, el estigma y la negligencia administrativa en los centros hospitalarios, no son pasivas, dado que se crean respuestas individuales y colectivas que son parte del capital social para enfrentar la epidemia.

\section{Contexto socioeconómico del lugar de estudio}

Los municipios del Soconusco tienen una economía basada principalmente en la agricultura de exportación, con cultivos como el plátano, el mango y el café. Desde finales del siglo XX, la migración de la población local ha ido en aumento ante la crisis en la producción agrícola, atraída en primer lugar hacia las principales ciudades del estado, como Tapachula, Tuxtla Gutiérrez y Huixtla, y, posteriormente, hacia otros estados del país y los Estados Unidos. Junto con los movimientos migratorios de los pobladores locales, se observa también inmigración de trabajadores centroamericanos, quienes cubren la necesidad de mano de obra para la producción agrícola de la región (Santacruz y Pérez, 2009).

En estos municipios, la Secretaría de Salud es la encargada de atender a residentes de Chiapas que no están integrados en algún centro laboral que les permita ser derechohabientes del Instituto Mexicano del Seguro Social (IMSS), del Instituto de Seguridad y Servicios Sociales de los Trabajadores (ISSSTE) o de la Secretaría de la Defensa Nacional (SEDENA). En Chiapas, la 
Secretaría de Salud, cuenta con diez jurisdicciones sanitarias. ${ }^{1}$ En Tapachula se encuentra la Jurisdicción Sanitaria VII, donde se coordinan acciones para atender a la población que reside en la región del Soconusco. Cuando realizamos el trabajo de campo, la atención directa a personas con VIH en esta zona se daba en dos hospitales de segundo nivel, uno ubicado en Huixtla y otro en Tapachula. A mediados del año 2010, también se creó en Tapachula el Centro Ambulatorio de Prevención y Atención de SIDA e Infecciones de Transmisión Sexual (CAPASIT).

\section{Estrategia para la recolección de los datos}

El análisis que presentamos se basa en una investigación de campo que se llevó a cabo de abril a agosto de 2010. Se entrevistó a 12 hombres — seis dijeron tener una orientación sexual homosexual, y seis, heterosexual-y siete mujeres (ver cuadro 1), siguiendo un guión de preguntas abiertas centradas en los sentimientos, preocupaciones y posibilidades de vida que los informantes se imaginaban para sí mismos y para su familia. Todos habían recibido el diagnóstico positivo a la prueba de VIH al menos un año antes, tiempo considerado por nosotros suficiente para elaborar respuestas a los problemas que trae un diagnóstico. Se realizaron charlas con personal de salud: un médico internista, el epidemiólogo del hospital y la encargada del programa de VIH/SIDA de la Jurisdicción Sanitaria VII, a quienes se cuestionó en torno a su experiencia en el hospital y con los pacientes. También se entrevistó al presidente de la asociación civil Una Mano Amiga en la Lucha contra el SIDA (UMA) y a una colaboradora de la misma organización, quienes compartieron la experiencia de la asociación con el personal de salud del Hospital General de Huixtla, a los pacientes y a sus familiares. Asimismo, tomando en cuenta que algunos informantes fueron trabajadores sexuales, se asistió a las mesas de discusión para debatir una propuesta de reforma del bando municipal y reglamento de sanidad de Tapachula, instrumentos legales que rigen el trabajo sexual en la región del Soconusco. ${ }^{2}$
Las entrevistas y las charlas se grabaron y posteriormente fueron transcritas. El análisis se realizó con el programa Atlas ti 5.0 (Friese, 2004).

Al inicio del proyecto se pretendió integrar dentro de la muestra a usuarios del hospital de Tapachula; sin embargo, el trabajo de campo coincidió con la apertura del CAPASIT y la reorganización en la atención de pacientes, por lo que no pudo llevarse a cabo en este centro. Nos acompañaron colaboradores de la asociación civil UMA, organización que trabaja desde hace más de diez años en la zona donde se llevó a cabo este trabajo, quienes nos presentaron a personal médico y pacientes. Se inició reclutando a informantes en la sala de espera, a quienes se les explicó el proyecto de manera individual y se les invitó a participar. Posteriormente, a su vez, ellos invitaron a sus compañeros o compañeras.

Los usuarios del Hospital General de Huixtla provienen de los siguientes municipios: Mapastepec, Acacoyagua, Acapetahua, Escuintla, Villa Comaltitlán, Huixtla, Tuzantán y Mazatán, ubicados en la región fronteriza con Guatemala. Todos hablan español como única lengua. En algunas localidades, como Huixtla y Mapastepec, se registran tasas de infección por VIH superiores a las 200 personas por cada 100000 habitantes, por lo que superan la media de la entidad, que es de 126 personas, y la nacional, que es de 130 personas (COESIDA Chiapas, 2011). Para establecer la muestra se siguió el criterio de saturación teórica (Rodríguez y García, 1999), que establece que el muestreo cesa cuando se considera que no habrá ningún dato adicional relacionado con las categorías estudiadas. El consentimiento informado se hizo de forma verbal y quedó grabado al inicio de cada entrevista.

El Hospital General de Huixtla se fundó en el año $1994 \mathrm{y}$, desde un principio, entre los pacientes que atiende están también aquellos relacionados con el VIH. De acuerdo con el representante de la organización UMA, existe, desde su creación, una colaboración entre las autoridades del hospital y las asociaciones civiles e instituciones gubernamentales, como la Comisión Nacional de Derechos Humanos. Eso ha marcado, dentro del hospital, una apertura y una sensibilidad especiales para este tipo de pacientes. Como ejemplo 
Francisco Chong-Villarreal, Carmen Fernández-Ćasanueva, Laura Huicochea-Gómez, Guadalupe del Carmen Álvarez-Gordillo, René LeYva-FLores

de esta colaboración, previamente a nuestro trabajo de campo, dicha organización y el Centro de Investigación en Salud de Comitán (CISC) realizaron talleres de sensibilización dirigidos a pacientes y a sus familiares, así como a médicos, enfermeras y psicólogos del hospital. De acuerdo con una psicóloga, las personas que allí se atienden se realizan la prueba cuando ya presentan síntomas relacionados con el SIDA o, en el caso de algunas mujeres, porque están embarazadas. Suelen llegar con acompañantes debido a que manifiestan una situación de debilidad física aguda que les impide llegar solas. Así es como las personas cercanas se enteran, también, del resultado.

Los datos obtenidos señalan que los informantes, cuando se quedan sin vivienda, sin trabajo o sin los recursos económicos suficientes para cubrir necesidades de alimentación y transporte, registran también cambios en su vida social. Algunos parientes que supieron del diagnóstico respondieron con agresión y, en ciertos casos, con el abandono. Pero hay también quienes, sabiéndolo, mantienen el silencio - dentro y fuera del ámbito doméstico - para garantizar el apoyo en forma de vivienda, alimentación y dinero que los hombres y mujeres afectados directamente utilizan para alimentarse y para asistir periódicamente al hospital a fin de recibir atención y medicamentos. De esa manera, disponen del recurso de la familia extensa y participan en estrategias encaminadas a la obtención de bienes materiales y económicos que les permitan conformar y mantener al grupo. Esta participación contrasta con la representación estigmatizada de las personas con $\mathrm{VIH}^{3}$ (Chong, et al., 2007), mediante la cual se las imagina aisladas, condenadas a una muerte inminente y víctimas inamovibles de la vulnerabilidad social en la que se encuentran inmersas.

\section{Elementos conceptuales para el análisis de los datos}

Para el análisis de la información resultado de este trabajo consideramos, al igual que lo hacen Sewell (1992) y Emirbayer y Mische (1998), ${ }^{4}$ que la acción humana se manifiesta dentro de un proceso de estructuración, que es la relación dinámica entre dicha acción individual o colectiva y las denominadas estructuras sociales, como la familia, la Iglesia, la comunidad o el Estado. Estas últimas, según Sewell (1992), constituyen organizaciones de relaciones sociales y son más o menos durables, creadas y recreadas a través de la práctica diaria de los actores sociales.

Las estructuras se conforman de reglas -o esquemas sociales - y recursos. Las primeras son los modelos de acción socialmente aceptados y con carácter normativo. Unas se encuentran en un nivel superficial, como los principios de acción que guían la práctica cotidiana, y otras tienen un carácter más formal, como las leyes. Por otra parte, los recursos sociales existen en el tiempo y en el espacio como características y posesiones específicas de los actores históricos (Morawska, 2001). Estos recursos están presentes en la mente, en las relaciones sociales, en el cuerpo físico y en el entorno social y físico inmediato de las personas, como son el conocimiento, ${ }^{5}$ la posición de poder dentro y fuera de la familia, así como las habilidades, el apoyo emocional y los bienes materiales de que disponen.

Un recurso social, dice Sewell (1992: 9), es cualquier aspecto que puede servir como fuente de poder para las personas en cualquier interacción social. Esta aseveración nos remite a la idea de "agencia social" que, según Sewell (1992: 20), consiste en el grado de control que las personas - agentes sociales - tienen sobre las relaciones sociales en las que están inmersos y que pueden sostener o transformar, dependiendo de sus deseos, temores y de las oportunidades de su entorno. En ese sentido, argumentan Ermibayer y Mische (1998: 970), por las respuestas interactivas a los problemas planteados por situaciones históricas cambiantes, un sujeto reproduce y transforma estructuras de manera intencionada o no intencionada.

A través de la capacidad agéntica, las personas con VIH que asisten al Hospital General de Huixtla, que viven inmersas en un contexto social con limitaciones para el desarrollo laboral y cultural, echan mano de la familia extensa, entendida ésta como un grupo unido por consanguinidad o afinidad - ascendentes, descendentes, laterales, parentesco 
político o ceremonial- (Spike et al., 2008). La familia extensa flexibiliza su composición para garantizar su reproducción a través de acciones destinadas a la sobrevivencia individual y del grupo (Del Ángel y Mendoza, 2002). Los individuos pueden elaborar "estrategias" - retomando el concepto de De Oliveira y Ariza (1999) - encaminadas a conformar y mantener al grupo. Estas acciones no implican una planeación racional, sino más bien una elección entre alternativas disponibles.

\section{La estrategia familiar, respuesta colectiva a la escasez de recursos económicos}

En nuestro estudio identificamos que, al momento de recibir el diagnóstico positivo a la prueba de VIH, los informantes viven con restricciones económicas: los hombres heterosexuales generalmente combinan actividades como jornaleros, que realizan en el campo según los ciclos de la producción agrícola, con otras actividades, como cargadores, vendedores ambulantes o albañiles; la mayoría de las mujeres reportó que antes del diagnóstico dependía económicamente de los ingresos de sus parejas; y los hombres homosexuales expresaron que obtenían ingresos a través de actividades en el sector servicios - como afanadores, meseros o dependientes de tiendas- o del trabajo sexual.

Todas las personas que participaron en esta investigación, antes de recibir el diagnóstico positivo contribuían en su familia, a la vez que se benefician de estrategias, de tal manera que prevalecía la colaboración de todos los miembros que conformaban la familia. Diferentes autores (Bazán, 1998; Del Ángel y Mendoza, 2002) observan que, ante las dificultades económicas, el grupo doméstico se muestra flexible para integrar a otros parientes distintos a los padres e hijos — familia nuclear-, como pueden ser las parejas de los hijos, los nietos, los abuelos o los tíos, con quienes comparten el espacio y los trabajos no remunerados, así como los recursos económicos y los alimentos. Nahmad, Carrasco y Nava (2009) argumentan que la flexibilidad para integrar en los beneficios a un mayor número de personas contribuye a garantizar la sobrevivencia del grupo frente a la pobreza, que se caracteriza por la carencia de recursos económicos y por la falta o escasez de servicios como luz y transporte. En la familia que reconocemos como extensa, la cercanía geográfica entre sus integrantes condiciona la colaboración mutua en las actividades que se realizan en la casa y en el intercambio de recursos, como lo ilustra el siguiente testimonio de una mujer que vive con su padre, su madre, dos hermanas pequeñas, su esposo y su hijo de seis años:

Mi mamá sale a vender empanada, atol, ya trae la comida. Yo barro todo el patio, le doy de comer, le lavo su ropa a mi mamá, nos da la comida. No muy gastamos en comida, solamente cuando tenemos algo de, dijera, se antoja pues. Compramos tortilla, la compramos las dos, compramos las botellas de agua, o sea que estamos unidos, pues. Allí mismo vamos a comer, allí todo, desayunamos, cenamos, todo. La luz la pago yo, pero porque tengo la tiendita y vendo refresco, vendo hielo, a veces hago bolis, o compro bolis hechos. De allí voy juntando, ya cuando voy a pagar la luz, de allí mismo sale, ya no saco de mi bolsa. El agua la paga mi papá, o sea que somos unidos (31 años).

Las amas de casa administran los recursos, se encargan de la limpieza, de la educación de los hijos y, en ocasiones, de los hermanos pequeños. Pueden también atender el negocio que da sustento al colectivo. Esa diversidad de actividades también se refleja en el caso de aquéllas cuyas parejas obtienen recursos de actividades agrícolas, como lo comenta una informante que a veces ayuda a su esposo agricultor en las actividades del campo.

No trabajo. Hago el aseo de mi casa, es la limpieza, que verá, como es tierrita mi casa, pues yo barro todo alrededor de mi casa, lavamos la ropa, sacudimos la casa y hacemos la comida. Cuando puedo ayudo a mi esposo a deshijar unas matas de café. Bueno, usted no se da la idea, así a quitar las hojitas, que tiene a la rama agobiado, tiene mucha fruta, bueno allí me voy a deshijar un ratito cuando puedo (40 años). 
Francisco Chong-Villarreal, Carmen Fernández-Ćasanueva, Laura Huicochea-Gómez, Guadalupe del Carmen Álvarez-Gordillo, René LeYva-FLores

Entre los recursos disponibles para el mantenimiento de la familia, es frecuente que se hable de los recursos económicos que provienen de programas federales como Oportunidades, ${ }^{6} 70$ y Más ${ }^{7}$ y Amanecer, ${ }^{8}$ que proporciona el gobierno del estado de Chiapas. Estos apoyos no solucionan los problemas de la pobreza, pero son significativos en las estrategias familiares. El relato de un jornalero ilustra su importancia. Él y su esposa son padres de dos hijos — de cinco y dos años - y no reciben directamente el dinero de ningún programa pero, como se verá en el testimonio, indirectamente se benefician de ello.

Pues con el dinero que ella [su madre] cobra de eso que le dan 70 y Más, que les viene como 800 pesos o 1000 pesos cada dos meses, de allí nos ayuda con unos 400 pesos, 300 pesos. Y con comida, frijolitos, arroz, que nos llega a dejar a la casa. [Por su parte, la suegra] pues ella me da menos, lo que le da es a ella, le da esté, o sea nos manda comida, como vivimos cerca, mi casa está aquí y ella está enfrente. Nos da comida o cualquier cosita que ella compra, siempre lo reparte (27 años).

En esta dinámica, los participantes en el estudio manifiestan la vivencia de circunstancias sociales, como la migración hacia Estados Unidos, que modifican la configuración del grupo ya que las remesas, en ocasiones, contribuyen a una mayor independencia económica de la familia nuclear con respecto a la familia extensa. Un ama de casa, en cuyo matrimonio ha procreado siete hijos - la mayor de 20 y el menor de cinco años - comenta cómo, tras la migración del esposo a los Estados Unidos, obtuvieron el dinero para comprar un terreno y lograr un grado de independencia con relación a sus suegros. ${ }^{9}$

Teníamos un terreno que eran tres cuerdas que nos regaló mi papá, hicimos la casa, cuarto, cocina, no bien hecho. De tablita, pero más o menos. Nos acomodamos, baños y todo. Después se fue mi esposo a Estados Unidos, vino, compró una camioneta, y ya largo tiempo, ahorró un poquito de dinero, 40000 pesos. Entonces en la venida de
ESTRATEGIAS FAMILIARES DE HOMBRES Y MUJERES CON VIH OUE BUSCAN ATENDER NECESIDADES MATERIALES EN LA REGIÓN DEL SOCONUSCO, ChIAPAS

allá tenía su dinero y siempre salía con la camioneta a hacer mandado. Le comentaron que vendían terreno acá (40 años).

Aún con la independencia ganada, el vínculo no se disuelve, sino que se mantiene el intercambio de recursos. Así lo expresa el marido cuando habla de la relación que ahora mantiene con su padre.

Él [el padre] a veces me visita y cuando me mira un poco bajo económicamente me dice, "mira hijo ten tus 500 pesos, para algo te ha de servir" y siempre he sido compartido. Porque cuando yo voy con él, y a veces se queja o lo miro a veces trabajando con la gente, dice "es que necesito algo pero no tengo, a ver dónde me cae, decimos, una chambita, para ganar algo con la gente." Entonces allí me da él a entender que está necesitado de algo, que no puede salir y si yo puedo le digo, mira papá, traigo tanto. Allí te dejo 400, 500 o 600 pesos, para algo le ha de ayudar. Aquí está, a veces un poco así, dice "iserá, mijo, que no te va a servir a ti??", n'hombre, no te preocupes, "algo te ha de servir a ti para los niños, en la casa.” No, le digo, ya yo veo la manera, pero ayúdese con esto. Y así, de esa manera nos hemos venido ayudando o ya sea en alimentación. Cuando yo voy, me dice, mira mijo llévate esa media caja de jabón. Ollévate este medio bulto de azúcar, o tengo este tanto de frijol que se está apolillando, o que ya no lo vamos a consumir, llévatelo. Entonces siempre nos hemos ayudado, así, de diferente manera (40 años).

\section{Formas de sobrevivencia a raíz del diagnóstico de $\mathrm{VIH}$ positivo}

En el Hospital General de Huixtla, cuando alguien recibe un diagnóstico de VIH positivo, lo hace con una representación estigmatizada del virus que le provoca sentimientos de miedo y vergüenza. Una madre de siete hijos lo expresa de la siguiente manera: "para mí era una preocupación. Era un miedo, que me daba miedo, pues" (40 años).

El estigma está presente en la comunidad. Una madre que tenía un niño de dos años y estaba 
embarazada de otro, cuando su cónyuge falleció por las complicaciones derivadas del SIDA, así lo expresa: "y llegó una señora a decirles [a su padre y a su madrastra], que iqué me tenían haciendo allí?, que yo los iba a contagiar a todos ellos" (34 años).

Para enfrentar el estigma, niegan y ocultan el diagnóstico y, a la par de ello, adquieren información en las visitas al hospital - a través de sus compañeros, del personal de salud y de colaboradores de alguna sociedad civil-, de tal manera que van reelaborando la construcción estigmatizada que ellas mismas tienen del virus. ${ }^{10}$ Así, evaden la marginación y el aislamiento que traería la certeza entre sus vecinos de su situación serológica.

El diagnóstico, además, plantea la necesidad de realizar gastos, los cuales serían más difíciles de cubrir si se perdiera el trabajo por complicaciones de la enfermedad, o si la pareja muriera y quien sobreviviera no realizara alguna actividad remunerada, como la mayoría de las amas de casa que se atienden en este centro.

Quienes permanecen juntos como matrimonio, usualmente mantienen la dinámica de sobrevivencia colectiva que tenían antes del diagnóstico, pero reajustan la distribución de los medios económicos disponibles para cubrir los costos del tratamiento, como gastos de transporte y alimentación para acudir al hospital. El siguiente testimonio de una paciente ilustra las dificultades que enfrenta para asistir a consulta mensual:

Caminamos una hora de camino, la venida. La ida, como una hora 15 minutos. Pos más o menos así, caminando, y a veces llevamos cuestión de comer, [como] frijol, pasta, algo de comer; pues ya nos lleva más, porque descansa uno el camino, y ahorita que está el paso, con esta agüita que llovió antenoche, así está el camino, bien tapado. La carretera, no hay paso. Estos días no va a subir carro porque está todo desboronado la carretera. Ahorita tenemos que subir caminando (40 años).

Las mujeres que enviudan, ${ }^{\text {ll }}$ o los hombres que no habían formado una pareja estable, replantean la dinámica que llevaban antes del diagnóstico, como lo dice un joven que a los 18 años recibe su diagnóstico y pierde su empleo: "era militar, por ese tiempo. Me dieron de baja por lo mismo, en el 2001, hice todo para quedarme" (27 años).

Las que enviudan y tienen hijos, por su parte, sin el apoyo de un marido, se enfrentan a la necesidad de obtener los recursos económicos para los gastos más elementales, como los que se requieren para la alimentación. Aquellas que vivían con la familia del esposo y una vez muerto continúan allí, algunas veces se sienten ajenas e incómodas. Así, regresan a la casa paterna, que tiene que reconfigurarse para darle cabida.

Para una mujer con VIH, sin experiencia laboral y además madre, buscar medios para la sobrevivencia puede parecer un desafío imposible de alcanzar en un contexto que no se caracteriza por un mercado laboral amplio, como se expresa en el testimonio de una de ellas, cuyo esposo trabajaba como jornalero en un rancho donde se cultiva papaya:

\section{No miraba yo salida, iqué voy hacer sola con dos niños, enferma y no poder trabajar? No sé ni cómo le hice en ese tiempo. A veces me pongo a pensar: Dios mío, ¿cómo le hice en ese tiempo? Mi hijo tomaba leche NAN de esa deslactosada, itan cara que es! (34 años).}

Los desafíos económicos que el VIH plantea para las mujeres que se quedan solas se resuelven en el contexto de la familia extensa. Salir de ese contexto para buscar un trabajo no es posible porque se ven a sí mismas como necesitadas del apoyo de familiares para vivir:

Ya no me siento igual, no me siento, pue, una persona normal. Que a veces digo yo que somos como viejitos, se tienen que andar cuidando mucho. Pues ya ves que los viejitos, allí se andan cuidando de cualquier enfermedad, débil, frágiles (34 años).

Para los hombres heterosexuales jóvenes que viven en la casa de la familia extensa, pero que esperaban construir una vida fuera de ella, el virus significó la cancelación de 
Francisco Chong-Villarreal, Carmen Fernández-Ćasanueva, Laura Huicochea-Gómez, Guadalupe del Carmen Álvarez-Gordillo, René LeYva-FLores

esa posibilidad. Uno de ellos, que supo de su diagnóstico a la edad de 15 años, comenta al respecto:

Me faltaba un año para salir de secundaria. Le dije a una mi tía que ya no iba a seguir estudiando. Ellas [las tías] me apoyaron, [me dijeron] que siguiera estudiando. Que ellas me iban a seguir apoyando. Terminé la secundaria, pero la prepa ya no quise estudiar. Pensaba en mi enfermedad, pensaba que nunca iba a tener una mujer. No iba a estar bien con mis estudios porque estaba muy ilusionado con ser militar (2l años).

Por otro lado, las personas que viven en otro estado del país o en otra comunidad del estado de Chiapas, planean el regreso con la familia cuando reciben el diagnóstico de VIH. Así le sucedió a un sujeto de 55 años que sostenía económicamente a su madre de 90, a quien, antes del diagnóstico, no visitaba desde hacía 17 años. Él vivía en Cancún, donde trabajó primero como encargado de seguridad en un hotel y, posteriormente, atendiendo una tienda de abarrotes:

Y a partir de allí me puse a pensar, me tengo que ir, me tengo que ir. Añorar mi lugar de origen, ime entiende? Porque si me pasa algo acá, no es lo mismo. Busco la familia, el hogar, el calor de ellos, la convivencia, porque eso nadie, nadie te lo puede dar. No es lo mismo (55 años)

Para las mujeres que enviudan, se agrega la dificultad que representa el cuidado de los hijos. Las posibilidades para resolver sus necesidades materiales son limitadas. Dentro del grupo doméstico se les imagina incapaces de independizarse, tal y como expresa una de ellas, que vive con sus padres, un hermano y el abuelo paterno, además de su hijo:

Me hubiera gustado ir a trabajar a algún otro lado, a México, que tuviera yo un sueldo para ayudarme más y ayudar a mi papá más, pero no me dejan ir ellos, uno por mi niño y otra por mi diagnóstico, no quieren que esté lejos (28 años).
ESTRATEGIAS FAMILIARES DE HOMBRES Y MUJERES CON VIH QUE BUSCAN ATENDER NECESIDADES MATERIALES EN LA REGIÓN DEL SOCONUSCO, CHIAPAS

\section{Las barreras del mercado laboral. Condiciones de vulnerabilidad social para personas con VIH}

Las escasas alternativas para laborar en la región provienen, como dijimos anteriormente, de un contexto productivo donde prevalece la agricultura de exportación sujeta a constantes crisis en la producción. Cuando las personas no se insertan en el trabajo agrícola, tienen como alternativa laborar en el área de servicios - como dependientes de una tienda de abarrotes, meseros o cocineros - y en el trabajo sexual, o insertarse en corporaciones militares como el Ejército o la Marina nacional. Quienes trabajan como meseros, cocineros y en el trabajo sexual, así como las personas que lo hacen en la armada de México, se enfrentan a reglas rígidas que determinan el despido de su trabajo. A partir de 2007, esta rigidez disminuyó en el Ejército (Gómez, 2007) ya que se modificó la Ley del Instituto de Seguridad Social para las Fuerzas Armadas Mexicanas, que establecía el despido de militares con VIH. La amenaza sigue vigente para quienes laboran como cocineros, encargados de bares, meseros, bailarinas o se dedican al trabajo sexual, y reciben el diagnóstico de cualquier infección de transmisión sexual, porque se les retira la tarjeta de control sanitario. ${ }^{12}$ Esta tarjeta es importante porque garantiza la aptitud para trabajar en cantinas y restaurantes, según el reglamento de sanidad que rige en los municipios de Chiapas, como Tapachula. Este reglamento expresa en su artículo 53:

Las personas que padezcan alguna de las enfermedades que establece el artículo anterior [se refiere a infecciones de transmisión sexual], están obligadas a suspender el ejercicio de la actividad que realizan y presentarse al reconocimiento médico, cuantas veces se les indique sometiéndose al tratamiento adecuado a efecto de evitar la transmisión de la enfermedad que padezca. ${ }^{13}$

Las escasas alternativas laborales configuran una situación de vulnerabilidad que puede empeorar las condiciones de salud en que viven las personas con cualquier problema de salud. La inflexibilidad del 
mercado laboral contrasta con la maleabilidad de las familias extensas que aquí analizamos, que parece no tener límites. Así lo expresa un entrevistado que vive en una zona rural. Él ha sido trabajador sexual, encargado de la limpieza de hospitales, dependiente de farmacia y empleado en el comercio informal.

[En ocasiones dice que le pregunta a su madre] ¿Qué va a comer? Se me antoja una pancita. Bueno, el 15 de este [mes] recibe sus 500 pesos. Si no hay comida, [comen] una salsa de tomate, chilito y cebolla. [iViven de los 500 pesos?] Apretadamente, no aflojadamente. [¿Cómo haces con tu ropa?] Yo no compro ropa de marca. Esto, mire, diez pesos, en la de paca. ${ }^{14}$ Mis pantalones, diez pesos. Esto me lo regaló Gerardo, mi amigo, mis zapatos. [iY el pasaje?] Mi mamá me lo da, pero vengo limitado. Ahora sí, mejor tomo agua, por allí paso a pedir agua en alguna casa, porque yo pierdo la vergüenza, a mí no me da vergüenza pedir (43 años).

\section{La familia extensa, un recurso social para enfrentar dificultades económicas de las personas con VIH}

Hemos destacado, hasta ahora, la flexibilidad en la recomposición de la familia para responder a los desafíos que provienen de las presiones económicas. El estigma está presente en todo este proceso, como lo prueba el silencio que mantienen sobre el diagnóstico (Chong et al., 2007). En algunos testimonios es evidente la fractura del grupo. Cuando eso sucede, se genera una nueva recomposición, como en el siguiente caso de un entrevistado que vive con su madre. Él cuenta con el apoyo económico y emocional de una hermana, de otros familiares y de vecinos que en ocasiones le proveen de frutas y hierbas comestibles. En su caso, sólo compartió el diagnóstico con la hermana, un hermano y la madre:

Tengo un hermano en Tuzantán. Me pegó una tos horrorosa, mi hermano es muy delicado. Tengo una ventana en el rancho [en la casa donde se encontraba]. ${ }^{15}$ [El hermano le dijo:] "Adiós, hermano, ya me voy." Así, dando la vuelta por todo el cerro. Mi
ESTRATEGIAS FAMILIARES DE HOMBRES Y MUJERES CON VIH QUE BUSCAN ATENDER NECESIDADES MATERIALES EN LA REgIÓN DEL SOCONUSCO, CHIAPAS

hermana, no. Mi hermana estuvo aquí en el hospital, única; [el hermano] se huyó, se fue de la casa (43 años).

Algunos hombres heterosexuales que no han formado pareja cuando reciben el diagnóstico, una vez resuelto el problema del estigma —ocultando la información-, tienen dos opciones de trabajo: el empleo en el campo y la participación en el negocio familiar. El trabajo en el campo es posible cuando la familia tiene terrenos propios, como el caso de un joven que conoció su diagnóstico a los 15 años.

Soy campesino, chaporreando el potrero, mi abuelito es el dueño, él me da trabajo. Eso he hecho desde pequeño. Nunca he hecho otra cosa. En otro lado no he trabajado. Vivo con mis abuelitos todavía, una mi tía y mis tres hermanos. Somos cinco, pero uno está casado y ya no vive con nosotros. Está el otro que sigue, es más grande que yo, después sigo yo y mis dos hermanitas, más pequeñas que yo, una tiene 15 y otra 18. Una estudia la secundaria y otra la prepa. Los más grandes trabajan también en el campo. No le pagamos la renta a mi abuelito, pero él nos paga para trabajar (2l años).

Otra opción de trabajo consiste en participar en algún negocio familiar, como lo refiere otro joven que trabajaba en el Ejército mexicano y fue despedido cuando recibió el diagnóstico de VIH positivo. Actualmente se encarga, junto con su madre, de vender pollos. Él los distribuye en la motocicleta y la madre los compra, los alimenta y se encarga de la reparación de la moto. En su casa viven sus padres, dos hermanos solteros, de 23 y 22 años, una hermana de 25 y la hija de la hermana —el esposo de la hermana se encuentra en los Estados Unidos y periódicamente les envía dinero-. El padre siembra café: "mi papá, que es campesino, se ocupa al café. Le echamos la mano mi mamá y yo. Con lo que ganamos, nos ayudamos, nos sirve para vestir y comer todos" (27 años)

Por su parte, las mujeres que enviudan obtienen recursos económicos generalmente del comercio informal —venta de ropa, de dulces o de alimentos-, actividad que realizan a la par de otras actividades, 
Francisco Chong-Villarreal, Carmen Fernández-C_asanueva, Laura Huicochea-Gómez, Guadalupe del Carmen Álvarez-Gordillo, René LeYva-FLores

como el lavado de ropa o la limpieza de casas ajenas. El negocio puede ser de la familia y, cuando éste no existe, es común encontrar que ellas crean el suyo propio con el apoyo de familiares. Una informante comparte cómo se inició en el negocio informal cuando no contaba con dinero ni mercancías para vender: "llegó una mi cuñada de fuera y me dijo, mira, te traigo tomate y cebolla para vender, para que te empieces a ayudar. Y sí, empecé a vender" (34 años).

Actualmente vive con sus dos hijos en la misma casa donde viven su padre y su madrastra. En relación con la distribución de los gastos, comenta:

Pues mi papá trabaja y le da su gasto a ella, digamos que los dos. Porque nos compartimos los gastos. Si vamos a comprar gas, entra las dos [su madrastra y ella]; si vamos a pagar luz, entre las dos; si vamos a comprar una comidita, entre las dos. Tú pones tal cosa y yo tanto. Ella, su mujer y yo llegamos a un acuerdo, si vamos a comprar una cosa, ah, está bien. Ya lo que es de mi hijos, sólo yo (34 años).

El negocio familiar o el que emprenden con apoyo de parientes serán también las opciones que tienen los hombres homosexuales para obtener recursos económicos. Aquellos que no mantienen un negocio realizan actividades en la casa. Tal es el caso de uno de ellos, que antes del diagnóstico era trabajador sexual y encargado de cantinas.

Yo a mi mamá le lavo su ropita, le barro patio, le trapeo cada tres días, pues, le lavo el sobrecama, todo le lavo a mi mamá. La ancianita me da mi comida, le dan su oportunidad [Programa Oportunidades] a mi mamá y ya me da mi dinerito (48 años)

Otra actividad que pueden realizar es la limpieza en casas de familiares y amigas, por la cual reciben algún pago en especie o en dinero.

Es que yo, mire, yo me gano, esas manos se ganan muchas cosas. Yo vengo a Huixtla, tengo un amigo gay, que vende pollo asado. Vive acá, le voy a lavar los trastes,
ESTRATEGIAS FAMILIARES DE HOMBRES Y MUJERES CON VIH QUE BUSCAN ATENDER NECESIDADES MATERIALES EN LA REGIÓN DEL SOCONUSCO, CHIAPAS

le lavo su ropa. Toda su familia me conoce, que soy gay y su hermano también. "iYa acabaste?" Ya, le digo. "Ya que lavaste la ropa, ivení, vamo a comer!, iqué querés, pollo asado o caldo de pollo?" Ah, caldo de pollo. Me pagan, no mucho 30,40 pesos, pero ya me voy comido y a veces le manda a mi mamá. "iLlévale a tu mamá su pollo asado, cuartito de pollo!" Yo ya voy lleno. Allá por donde vive Raúl. Hay una amiga también, pero mujer. "Manita, ite hago el aseo?" Me pongo a barrer y a trapear. “'Lavá mi ropa manito, mis sabanas!". Bueno, mis 50 pesos, así me la paso (43 años).

A la par que reciben dinero por la colaboración y el apoyo a su familia, desarrollan su propia estrategia para aprovechar los recursos al máximo y cubrir sus necesidades. En relación con las consultas, por ejemplo, la psicóloga del hospital comenta que, en el caso de las parejas, en ocasiones sólo asiste uno de ellos, quien lleva sus medicamentos y también los del que no asistió. Así se ahorran el costo que supondría que acudieran ambos. $^{16}$

En esa situación de carencias económicas, algunas personas también optan por no asistir a consultas o a eventos considerados por ellas como secundarios, como lo expresa una madre de dos hijos, de ocho y seis años:

De hecho no vine a cita de ginecología, por lo mismo de mis pasajes. Digo, que es más importante las citas con el médico y cargas virales y allí sí me muevo. Digo, ¿ginecólogo? No, sí me gustaría seguir viniendo a las pláticas, pero también mis pasajes. Eso me detiene (26 años).

Pese a las dificultades, los informantes perciben que, incluso con carencias, resuelven sus necesidades aunque sea mínimamente, como lo expresa un cargador de bultos de café que, cuando no hay trabajo de cargador o se encuentra enfermo, vende elotes hervidos con sus hijos: "Allí le vamos pasando, le digo. Poco a poco, porque no alcanza. La verdad, no da, pue. Pero voy saliendo, gracias a diosito lindo" (38 años).

La familia extensa es un recurso social disponible aún en condiciones de pobreza, como se ha descrito 
hasta ahora. Todas las personas informantes que participaron en este trabajo disponen y utilizan este recurso social.

\section{Conclusiones}

En este trabajo, que se centra en las estrategias familiares para enfrentar necesidades materiales de hombres y mujeres con VIH, estamos conscientes de que el efecto del estigma pesa sobre ellos. Algunos informantes han vivido un proceso de rechazo, discriminación y recomposición grupal. Seleccionamos para la muestra a quienes al menos hacía un año que habían recibido el diagnóstico, tiempo que consideramos mínimo suficiente para realizar las adaptaciones necesarias en el grupo donde conviven y reciben apoyo. Para su supervivencia, el apoyo familiar ha sido fundamental. Es posible que, para quienes no hayan alcanzado ese tiempo de vida, la falta de apoyo haya sido el factor ausente. Pero también los participantes en el estudio pudieron no haber sobrevivido, tomando en cuenta que llegaron al Hospital General de Huixtla en su mayoría con problemas de salud relacionados con el SIDA.

Al igual que Parker y Aggleton (2002), partimos de la convicción de que el estigma asociado al VIH tiene un efecto inutilizador. Retomando elementos conceptuales de la teoría de la estructuración para tener la perspectiva adecuada, destacamos aspectos que también demuestran que las personas no son pasivas. Ante las adversidades, buscan recursos para enfrentarlas y, eventualmente, hacer trasformaciones en el contexto en el que se encuentran. Un ejemplo de transformación es el que realizan de la construcción social del VIH con argumentos que van adquiriendo en su experiencia con el padecimiento, y que comparten con familiares y vecinos, lo que disminuye en alguna medida la carga de estigma que contiene.

Encontramos en el Hospital General de Huixtla un personal de salud que ha trabajado en su propia sensibilización, lo cual fue reconocido en las entrevistas. Seguramente, en otros centros de salud la cantidad de trabajadores sensibilizados es notablemente menor, lo cual incrementa las dificultades de los pacientes para enfrentar los obstáculos relacionados con su padecimiento. Tal vez en esos lugares encontremos otras estrategias para construir respuestas mínimas necesarias para la sobrevivencia.

\section{Notas}

'Lasjurisdiccionessanitariassoninstanciasadministrativas de la Secretaría de Salud que coordinan diferentes programas de salud. Cada jurisdicción sanitaria tiene un programa de VIH/SIDA, que coordina estrategias de prevención y atención a personas afectadas por el VIH.

${ }^{2}$ En los meses de agosto y septiembre de 2010, a raíz de una serie de redadas policíacas donde se detenía y exponía en los medios impresos de Tapachula a hombres homosexuales acusándolos de ejercer trabajo sexual (Islas, 2009; González, 2009), se realizaron mesas de trabajo en la presidencia municipal de esa ciudad promovidas por la asociación civil Una Mano Amiga en la Lucha contra el SIDA. Se propuso una reforma del reglamento de sanidad municipal. En las mesas de trabajo participaron organizaciones de la sociedad civil como UMA, Medilex, la organización Diversidad y Género, representantes de instancias gubernamentales como la Comisión Nacional de Derechos Humanos, el Instituto Nacional de Salud Pública y representantes del gobierno municipal de Tapachula.

3 Entendemos por estigma asociado al VIH/SIDA la construcción social del virus, que lo asocia a la muerte inminente así como a grupos estigmatizados, por ejemplo, a mujeres trabajadoras sexuales y homosexuales, al uso de drogas y al sexo que no tiene como finalidad la reproducción humana. Esta construcción tiene una connotación moral que genera sentimientos de vergüenza, culpa y miedo, así como rechazo y discriminación (USAID, 2006).

${ }^{4}$ Los conceptos para el análisis de este documento fueron tomados de la teoría de la estructuración desarrollada en un principio por Bourdieu (1977) y Giddens (1976), y reconceptualizada por Stones (2005), Emirbayer y Mische (1998) y Sewell (1992). Se destaca en la reconceptualización la capacidad del sujeto para transformar estructuras sociales. En ese sentido, y 
Francisco Chong-Villarreal, Carmen Fernández-Ćasanueva, Laura Huicochea-Gómez, Guadalupe del Carmen Álvarez-Gordillo, René LeYva-FLores

considerando la noción de habitus de Bordieu (1977), como contexto estructural que moldea la agencia o práctica humana, donde la agencia humana resulta habitual y repetitiva, Emirbayer y Mische (1998) establecen que, para que la agencia se capture en su completa complejidad, debe situarse dentro del flujo del tiempo. Así, el contexto estructural de la acción no aparece fijo, sino temporal. La agencia humana está inmersa en un contexto de estructuras que se traslapan, contradicen y cambian. De esta manera, se entiende que el medioambiente estructural de la acción humana es sostenido y, a la vez, alterado por la agencia humana.

${ }^{5}$ Incluso el conocimiento de las reglas o esquemas sociales es también un recurso que contribuye a mantener o transformar un orden social (Sewell, 1992).

${ }^{6}$ El programa Oportunidades se destina a población que vive en extrema pobreza y tiene tres componentes: salud, alimentación y educación. Este programa establece la ayuda a través de la atención en salud, la educación y el apoyo económico que se distribuye cada dos meses (SEDESOL, 2009). Los recursos que se reciben por este programa varían según la edad y el grado en que estudian. ${ }^{7}$ El programa 70 y Más es federal y busca mejorar la calidad de vida de los adultos mayores a través de un apoyo económico de 1000 pesos, que se da bimestralmente a personas mayores de 70 años (SEDESOL, 2010).

${ }^{8}$ El programa Amanecer da apoyo a personas mayores de 64 años, quienes se benefician con 550 pesos mensuales (DIF Chiapas, 2009).

${ }^{9}$ Si bien la migración abre la posibilidad de mayores ingresos económicos, Kendall y Vázquez (2004) han documentado cómo la migración masculina hacia los Estados Unidos genera riesgos para adquirir el VIH que afectan a la familia.

${ }^{10}$ La respuesta al estigma fue analizada en un trabajo (Chong et al., 2012) donde se destacó que el silencio en torno al diagnóstico es una estrategia para enfrentar un mayor rechazo social.

${ }^{11}$ De la muestra estudiada, sólo un hombre con tres hijos era viudo. Este hombre continuó trabajando como cargador de bultos de café. Para el cuidado de los hijos contó con el apoyo de las hermanas de la esposa fallecida y de su propia madre.
ESTRATEGIAS FAMILIARES DE HOMBRES Y MUJERES CON VIH QUE BUSCAN ATENDER NECESIDADES MATERIALES EN LA REGIÓN DEL SOCONUSCO, CHIAPAS

${ }^{12}$ La tarjeta de control sanitario es un mecanismo que pretende controlar el trabajo sexual, pero en realidad se convierte en mecanismo de mayor explotación. En una colaboración para un trabajo (Quintino et al., 201la), tuvimos la oportunidad de conversar con mujeres trabajadoras sexuales que ejercen esta actividad de forma clandestina - esperan a clientes en parques, calles y salidas de hoteles-. Algunas nos comentaron que sólo pueden tener una tarjeta si trabajan en algún establecimiento, pero eso las obliga a consumir grandes cantidades de alcohol y a cubrir un horario generalmente nocturno. El trabajo sexual clandestino les da más libertad para organizar su horario y para disponer de más tiempo para sus hijos. Sin embargo, esa situación las expone a la constante extorsión de policías, quienes cobran una cuota para "permitirles" seguir laborando.

${ }^{13}$ De acuerdo con la reforma planteada, durante las mesas de trabajo que se llevaron a cabo de agosto a septiembre de 2010 (ver nota 2), el artículo 53 quedó de la siguiente manera: "Artículo 53-1. Si alguna persona es reactiva a la prueba de VIH, deberá garantizarse la confidencialidad de la prueba, así como la información, la atención psicológica y médica, canalizándola con grupos organizados de la sociedad civil y con las instancias de salud competentes. Artículo 53-2. El propietario deberá encontrar alternativas de trabajo dentro del establecimiento, diferentes al sexo servicio, para la persona infectada por el VIH o seropositiva." Rosember López Samayoa, en el año 2010, cuando nos entregó esta propuesta de reforma, aseveró que la redacción fue elaborada por Rosa María Yáñez Clavel, de la organización Medilex, quien ha asesorado legalmente a grupos vulnerables, como lo fueron en su momento los militares que adquirían el VIH y pelearon por mantener su trabajo en el Ejército.

${ }^{14}$ En la región hay negocios donde se vende ropa usada. Las personas de la región le llaman "ropa de paca".

${ }^{15}$ En esta región, las personas llaman "rancho" tanto al terreno rural, como a la casa que se ha construido en ese terreno.

${ }^{16}$ Estos actos se pueden llevar a cabo porque hay una sensibilidad en los trabajadores de salud del hospital 
de Huixtla que es reconocida por pacientes y por activistas defensores de los derechos de personas con $\mathrm{VIH}$, como quienes conforman la asociación civil Una Mano Amiga en la Lucha contra el SIDA, A.C. Pero no es la norma en la atención de las personas con VIH (Infante et al., 2006). En una charla que sostuvimos con un médico que atiende el área de urgencias del hospital de Huixtla, nos comentó que las personas que entran a laborar no siempre comparten esa actitud de solidaridad con las personas con VIH, y plantea la necesidad de un proceso de sensibilización permanente al personal de salud en temas de estigma y discriminación.

\section{Referencias bibliográficas}

Bazán, Lucía (1998), "El último recurso: las relaciones familiares como alternativas frente a la crisis", ponencia presentada en LASA98, Mesa de Trabajo, Familia y Comunidad, Chicago: Latin American Studies Association. 〈http://lasa.international.pitt. edu/LASA98/Bazan.pdf> [1 de diciembre de 2012].

Bronfman, Mario, René Leyva, Mirka Negroni, Celina Rueda y Daniel Hernández (2004), "Antecedentes", en Mario Bronfman, René Leyva y Mirka Negroni (coords.), Movilidad poblacional y VIH/SIDA, México: Instituto Nacional de Salud Pública, pp. 13-34

Chong Villarreal, Francisco, Teresa Torres López y Berenice López Coutiño (2007), "La representación socialdel SIDA en jóvenes de tres ciudades de México", en Rolando Tinoco, María Martínez y Angélica Evangelista (eds.), Compartiendo saberes sobre VIH/ SIDA en Chiapas, Chiapas: Centro de Investigaciones en Salud de Comitán/Instituto de Salud del Estado de Chiapas/Consejo Estatal de Población/Fondo de Población de las Naciones Unidas/El Colegio de la Frontera Sur, pp. 141-160.

Chong Villarreal, Francisco, Carmen Fernández, Laura Huicochea, Guadalupe Álvarez y René Leyva (2012), "Estrategias de personas con VIH para enfrentar el estigma asociado al VIH/SIDA. Pacientes del Hospital General de Huixtla, Chiapas", en Estudios Fronterizos, Nueva Época, vol. 13, núm. 25, pp. 31-56.
COESIDA Chiapas (2011), Situación del VIH/SIDA en el estado de Chiapas. Tarjetas ejecutivas, Chiapas: Instituto de Salud del Estado.

De Oliveira, Orlandina y Marina Ariza (1999), "Trabajo, familia y condición femenina: una revisión de las principales perspectivas de análisis", en Papeles de Población, vol. 5, núm. 20, Toluca: Universidad Autónoma del Estado de México, pp. 89-127.

Del Ángel Pérez, Analid y Martín Mendoza Briseño (2002), "Familia totonaca, expresión cultural y sobrevivencia”, en Papeles de Población, núm. 32, Toluca, México: Universidad Autónoma del Estado de México, pp. 96-121. 〈http://redalyc.uaemex.mx/ pdf/112/11203204.pdf $>$ [1 de diciembre de 2012].

Department for International Development (DFID) (2007), Taking action against HIV stigma and discrimination. Guidance document and supporting resources, Londres: Department for international Development.

DIF Chiapas (2009), Amanecer, Tuxtla Gutiérrez: Gobierno del Estado de Chiapas, 〈http://www. difchiapas.gob. $\mathrm{mx} /$ index.php?option=com content\&view=article\& $\&$ id=27> $[1$ de diciembre de 2012].

Emirbayer, Mustafá y Ann Mische (1998), "What is Agency", en The American Journal of Sociology, vol. 103, núm. 4, pp. 962-1023.

Evangelista, Angélica, Rolando Tinoco y María Martínez (2007), "Vulnerabilidad y riesgo al VIH, en mujeres rurales de la Región Fronteriza de Chiapas", en Rolando Tinoco, María Martínez y Angélica Evangelista (eds.), Compartiendo saberes sobre VIH/ SIDA en Chiapas, Chiapas: Centro de Investigaciones en Salud de Comitán/Instituto de Salud del Estado de Chiapas/Consejo Estatal de Población/Fondo de Población de las Naciones Unidas/El Colegio de la Frontera Sur, pp. 37-56.

Evangelista, Angélica y Edith Kauffer (2007), “Jóvenes y VIH/SIDA: contextos de vulnerabilidad en comunidades de la Región Fronteriza de Chiapas", en Rolando Tinoco, María Martínez y Angélica Evangelista (eds.), Compartiendo saberes sobre VIH/ SIDA en Chiapas, Chiapas: Centro de Investigaciones en Salud de Comitán/Instituto de Salud del Estado 
Francisco Chong-Villarreal, Carmen Fernández-Ćasanueva, Laura Huicochea-Gómez, Guadalupe del Carmen Álvarez-Gordillo, René LeYva-FLores

de Chiapas/Consejo Estatal de Población/Fondo de Población de las Naciones Unidas/El Colegio de la Frontera Sur, pp. 77-98.

Fasce, Ninoshka (2008), "Depression and social support among men and women living with HIV", en Journal of Applied Behavioral Research, vol. 12, núm. 4, pp. 221-236.

Friese, Susane, User's Manual for ATLAS.ti 5.0, software for qualitative data analysis, management and model building, Berlín: Advisor, Resarch Talk Inc.

García Sosa, Juan Carlos, Sergio Meneses Navarro y Sebastiana Palé Pérez (2007), “Migración internacional indígena y vulnerabilidad ante el VIH/ SIDA. Los chamulas entre barras y estrellas", en Liminar. Estudios Sociales y Humanísticos, vol. 5, núm. 1, San Cristóbal de Las Casas: Centro de Estudios Superiores de México y Centroamérica-Universidad de Ciencias y Artes de Chiapas, pp. 119-144.

Gómez Leyva, Ciro (2007), "El soldado con VIH que derrotó al Ejército Mexicano. La historia en Breve”, en Milenio Online, 28 febrero. 〈http://impreso.milenio. com/node/7026239> [1 de diciembre de 2012].

Gómez, Gregorio, Carmen Velazco, Laura Gómez, Olivia Ochoa, Aracely Marquina, Elicenia Velazquez, Rosember López y Francisco Chong (2012), Informe final. Evaluación para el fortalecimiento de la respuesta del sistema estatal de salud al VIH en las jurisdicciones VII Tapachula, VIII Tonalá y Motozintla del estado de Chiapas, México, Tuxtla Gutiérrez: Gobierno del Estado de Chiapas-Programa Estatal de VIH/SIDA.

González, Rosario (2009), "Aseguran a chicos del 'tacón dorado", en Diario del Sur, Tapachula, Chiapas, 16 de octubre, p. 1 .

Infante, César, Ángel Zarco, Silvia Magali Cuadra, Ken Morrison, Marta Caballero, Mario Bronfman y Carlos Magis (2006), "El estigma asociado al VIH/SIDA. El caso de los prestadores de servicios de salud en México", en Salud Pública de México, vol. 48, núm. 2, marzo-abril, pp. 141-152.

Islas, Álvaro (2009), "Detienen a homosexuales en el primer cuadro de la ciudad", en Semanario El Orbe, Tapachula, Chiapas, lunes, 26 de octubre, p. 1.

Kendall, Tamil y Hilda Pérez Vázquez (2004), Hablan las mujeres mexicanas VIH positivas. Necesidades y apoyos en el
ESTRATEGIAS FAMILIARES DE HOMBRES Y MUJERES CON VIH QUE BUSCAN ATENDER NECESIDADES MATERIALES EN LA REGIÓN DEL SOCONUSCO, CHIAPAS

ámbito médico, familiar y comunitario, México: Colectivo Sol/Red Mexicana de Personas que Viven con VIH/ Gobierno del Distrito Federal.

Morawska, Ewa (2001), "Structuring migration: the case of polish income-seeking travelers to the west", en Theory and Society, núm. 30, pp. 47-80.

Nahmad, Salomón, Tania Carrasco y Elena Nava (2009), "Elementos para la construcción de una tipología de la pobreza rural en México”, en CLACSO, Retos para la integración social de los pobres en América Latina, Buenos Aires: CLACSO, pp. 351-378.

Ogden, Jessica y Laura Nyblade (2005), Common at Its Core: HIV-Related Stigma Across Contexts, Washington: International Center for Research on Women.

Parker, Richard, Peter Aggleton (2002), Estigma y discriminación relacionados con el VIH/SIDA. Un marco conceptual eimplicaciones para la acción, documento de trabajo núm. 9, México: Programa de Salud Reproductiva y Sociedad-El Colegio de México.

Quintino, Frida, René Leyva, Mónica Cerón y Elbia Guzmán (201la), "El contexto: salud y migración en la frontera México-Guatemala”, en René Leyva y Frida Quintino (eds.), Migración y salud sexual y reproductiva en la frontera sur de México, México: Instituto Nacional de Salud Pública/UNFPA, pp. 37-50.

Quintino, Frida, René Leyva, Francisco Chong, Nelly Gómez, Paola Alcalá y Rosember López (201lb), "Trabajadoras sexuales en la frontera MéxicoGuatemala: vulnerabilidad y acceso a servicios de salud sexual y reproductiva”, en René Leyva y Frida Quintino (eds.), Migración y salud sexual y reproductiva en la frontera sur de México, México: Instituto Nacional de Salud Pública/UNFPA, pp. 107-126.

Rodríguez Gómez, Gregorio y Eduardo García Giménez (1999), Metodología de la investigación. España: Aljibe.

Santacruz de León, Eugenio Eliseo y Elba Pérez Villalba (2009), "Atraso económico, migración y remesas: el caso del Soconusco, Chiapas, México", en Convergencia. Revista de Ciencias Sociales, núm. 50, México: Universidad Autónoma del Estado de México, pp. 57-77. 
Secretaría de Desarrollo Social (SEDESOL) (2009), Programa Oportunidades, México: Secretaría de Desarrollo Social. 〈http://www.seguro-popular.salud.gob.mx/index. php?option=com_content\&view=article\&id=13\&\&Item id $=37>$ [1 de diciembre de 2012].

Secretaría de Desarrollo Social (SEDESOL) (2010), 70 y Más, adultos mayores, México: Secretaría de Desarrollo Social. 〈http://www.presidencia.gob.mx/ infografias/2010/08/03/setentaymas/index.html> [1 de diciembre de 2012].

Sewell, William (1992), "A Theory of Structure: Duality, Agency and Transformation”, en The American Journal of Sociology, vol. 98, núm. 1, julio, pp. 1-29.

Spike, Tamara, Lindsey Harrington y Matthew Harrington (2008), "Si todo el mundo fuera Inglaterra: la teoría de Peter Laslett sobre la composición de los grupos domésticos vs. la realidad tapatía, 1821-1922", en Estudios Sociales. Nueva Época, núm. 2, pp. 25-38.

USAID (2006), Breaking the Cycle: Stigma, Discrimination, Internal Stigma and HIV, Washington: United States Agency for International Development.

Vega Angarita, Olga Marina y Dianne Sofía González Escobar (2009), "Apoyo social: elemento clave en el afrontamiento de la enfermedad crónica”, en Enfermería Global, vol. 8, núm. 2, pp. 1-1l.

Villa, Blanca, Antonio Tapia, Marta. Caballero, Anahi Dreser, Silvia Cuadra, Tonatiuh González, René. Leyva, Claudia Guerrero y Mario Bronfman (2004), "México, Ciudad Hidalgo, Chiapas", en Mario Bronfman, René Leyva y Mirka Negroni (coords.), Movilidad poblacional y VIH/SIDA, México: Instituto Nacional de Salud Pública, pp. 275-302. 
Cuadro 1. Datos generales de los informantes

\begin{tabular}{|c|c|c|c|c|c|c|c|}
\hline Sexo & $\begin{array}{l}\text { Edad } \\
\text { (años) }\end{array}$ & $\begin{array}{l}\text { Tiempo de } \\
\text { diagnóstico } \\
\text { (años) }\end{array}$ & $\begin{array}{l}\text { Edad al recibir } \\
\text { el diagnnóstico } \\
\text { (años) }\end{array}$ & $\begin{array}{l}\text { Número } \\
\text { de hijos }\end{array}$ & $\begin{array}{l}\text { Estado } \\
\text { civil }\end{array}$ & $\begin{array}{l}\text { Actividad } \\
\text { actual }\end{array}$ & Escolaridad \\
\hline \multirow{7}{*}{ Mujeres } & 31 & 7 & 24 & 1 & unión libre & comerciante & $\begin{array}{l}\text { cuarto de } \\
\text { primaria }\end{array}$ \\
\hline & 40 & 5 & 35 & 7 & casada & ama de casa & 0 \\
\hline & 34 & 7 & 27 & 2 & viuda & comerciante & $\begin{array}{l}\text { tercero de } \\
\text { secundaria }\end{array}$ \\
\hline & 28 & 4 & 24 & 2 & viuda & comerciante & $\begin{array}{c}\text { tercero de } \\
\text { preparatoria }\end{array}$ \\
\hline & 26 & 6 & 20 & 2 & viuda & desempleada & secundaria \\
\hline & 23 & 1 & 22 & 2 & casada & ama de casa & 0 \\
\hline & 59 & 7 & 52 & 5 & divorciada & comerciante & $\begin{array}{l}\text { tercero de } \\
\text { primaria }\end{array}$ \\
\hline \multirow{6}{*}{$\begin{array}{l}\text { Hombres } \\
\text { homosexuales }\end{array}$} & 55 & 6 & 49 & 0 & soltero & vigilancia & $\begin{array}{l}\text { tercero de } \\
\text { secundaria }\end{array}$ \\
\hline & 42 & 3 & 39 & 0 & soltero & desempleado & $\begin{array}{l}\text { sexto de } \\
\text { primaria }\end{array}$ \\
\hline & 48 & 3 & 45 & 0 & soltero & desempleado & $\begin{array}{c}\text { tercero de } \\
\text { primaria }\end{array}$ \\
\hline & 28 & 1 & 27 & 0 & soltero & comerciante & $\begin{array}{c}\text { tercero de } \\
\text { preparatoria }\end{array}$ \\
\hline & 28 & 4 & 24 & 0 & soltero & comerciante & $\begin{array}{l}\text { tercero de } \\
\text { secundaria }\end{array}$ \\
\hline & 42 & 4 & 38 & 1 & soltero & desempleado & $\begin{array}{l}\text { sexto de } \\
\text { primeria }\end{array}$ \\
\hline \multirow{6}{*}{$\begin{array}{l}\text { Hombres } \\
\text { heterosexuales }\end{array}$} & 40 & 5 & 35 & 7 & casado & agricultor & $\begin{array}{l}\text { cuarto de } \\
\text { primaria }\end{array}$ \\
\hline & 27 & 1 & 26 & 2 & casado & jornalero & 0 \\
\hline & 27 & 9 & 18 & 1 & soltero & comerciante & $\begin{array}{l}\text { segundo de } \\
\text { secundaria }\end{array}$ \\
\hline & 21 & 6 & 15 & 0 & casado & jornalero & $\begin{array}{c}\text { tercero de } \\
\text { preparatoria }\end{array}$ \\
\hline & 38 & 3 & 35 & 2 & viudo & cargador & $\begin{array}{l}\text { tercero de } \\
\text { secundaria }\end{array}$ \\
\hline & 33 & 2 & 31 & 1 & separado & desempleado & $\begin{array}{l}\text { tercero de } \\
\text { secundaria }\end{array}$ \\
\hline
\end{tabular}

Fuente: elaboración propia. 